\title{
Effects of Floral and Foliage Displays on Human Emotions
}

M. Adachi, ${ }^{\text {C C.L.E. Rohde, }}{ }^{2}$ and A. D. Kendle ${ }^{2}$

AdDitional INDEX wORDs. cut flowers, feelings, foliage plants, horticultural therapy, human emotions, mood, psychological responses to nature

Summary. C hanges in human emotions were investigated during exposure to three different indoor conditions: floral display present, foliage display present, and no display present. There were 20 subjects (10 males and 10 females) in each condition. The subjects were shown a video that introduced the $U$ niversity of Reading and included scenes of landscapes. It was shown that a floral display had positive effects on human emotions, such as composition and confidence, however, some evidence of a significant increase in annoyance was also found for this treatment. The foliage display had a somewhat negative effect by slightly increasing bad temper, and the foliage display tended to have a positive effect on clearheadedness. I nvestigations of psychological responses to nature are complex, and many opportunities for more work exist.

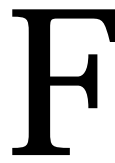

lowers have been important from the earliest times as social, aesthetic, and spiritual symbols. There have been many horticultural research studies on flower growth; however, until recently there has been surprisingly little research on the fundamental question of the appreciation and motivation for the use of flowers. There are several attributes that contribute to the attractive qualities of flowers, including color, shape, fragrance, change during development, and the situations they are found in (D oyle et al., 1994). Yet we know little about the psychological response of people to flowers.

It has been suggested that there is some innate or genetically programmed mechanism for the human response to nature and that a preestablished harmony between nature and human beings can influence our well-being or emotional state (Conklin, 1972; Kaplan and Kaplan, 1982). People often benefit from contacts with images of plants, as well as benefit from contact with real nature (Rohde and Kendle, 1994).

Foliage plants and indoor landscaping have received research attention (Furuta, 1983; Lohr et al., 1996). Cut flowers are also important as indoor decoration, for example, as part of table settings. H owever, there is very little academic research that investigates the psychological effects of cut flowers (M atsuo, 1992; Shoemaker et al., 1992). The investigation could help people to make better aesthetic use of flowers as interior ornaments.

We thank $\mathrm{D}$ iane Relf and R oger $\mathrm{U}$ Irich for generous advice in the paper. The cost of publishing this paper was defrayed in part by the payment of page charges. U nder postal regulations, this paper therefore must be hereby marked advertisement solely to indicate thisfact. 
In this study, all the subjects were presented with a video screen around which floral or foliage displays or no displays were placed, so the research aimed to investigate how flowers affect mood and emotional state in people consciously and unconsciously, and to compare the effect of cut flowers with foliage plants.

\section{Materials and methods}

Theexperiment took placein summer 1996. Experimental subjectswere asked to watch a video about the U niversity of Reading. They also completed questionnaires about their feelings before and after entering a treatment room of one of three different display conditions consecutively provided in a room at the U niversity. These were floral arrangements, foliage arrangements or no display. A windowlessroom wasselected to avoid any effect of outside scenery on emotions (U Irich, 1984).

Three flower vases were used for the floral display. These contained mainly white and pink sweet peas (LathyrusodoratusL.). The sweet peas produced a dominant fragrance that filled the room. There were also delphinium (Delphinium L.) in blue and white, goat's beard (A runcus di oicus Kostel. 'Kneiffii'), goat's rue (Galega orientalis L.) without flowers, purple woodland phlox (Phlox divaricata subsp. laphamii Wood), burgundy bearded tongue (Penstemon $M$ itch. ' Garnet'), and dark blue sage (Salvia nemerosa L.) contained in the floral display. T wo of the flower vases were placed on the sides of the video screen, and the other one was placed on the table where the subjects completed the questionnaire. In the foliage display, these five popular potted foliage plants were placed beside the video screen and on the table: banana (M usa L.), philodendron (Philodendron Schott), grape ivy (Rhoicissus rhomboi dea (E M ey. exH arv.) Planch.), boston fern ( $\mathrm{N}$ ephrolepis exaltata Schott), and parlor palm (Chamaedorea elegansWilld.).

Of the subjects, 53 were students at the U niversity of Reading and 5 were community members. The students were majors in agriculture, botany, construction management, economics, education, engineering, english literature, food science, horticulture, international relationships, law, linguistics, physics, psychology, and soil science. There were 17 nationalities represented by the subjects: 19 British, 19 Japanese, 3 Chinese, 2 Kenyan, 2 Malaysian, 2 Taiwanese, and 1 each of Bangladeshi, Ethiopian, German, Indian, Korean, M auritius, N epalese, Portuguese, Romanian, Saudi A rabian, and T urkish. A bout 20 people participated as subjectsfor each display type. A balance between males and females was maintained in the subject sample. In no plant display, two of subjects were 20 years old or younger, nine were 21 to 25 years old, and eight were between 25 and 41 years old. In the floral display group, three were 20 years old or younger, eight were 21 to 25 years old, and eight were between 25 and 35 . In the foliage display group, four were 20 or younger, three were 21 to 25 years old, and twelve were between 25 and 41 years old.

Subjects completed a questionnaire that recorded their initial mood (mood scale 1) (scale described below). A videotape was then shown which introduced the U niversity of Reading for $19 \mathrm{~min}$. The subjects believed that the quality of the tape was the main purpose of the research, so their attention was not focused on the plants. $\mathrm{H}$ opefully response bias based on the room displays was eliminated. They then completed the mood questionnaire again before leaving (mood scale 2). The changes in moods of the subjects were then compared relative to the different displays.

The mood questionnaire measured six different moods. It consisted of 24 individual visual analogue scales, assessing two negative and two positivefeelingsfor each mood. Themoods measured are those which are assessed by the $\mathrm{BI}$-Polar Form of the Profile of M ood States (POM S-BI) (L orr and $M c N$ air, 1984). The mood questionnaire used a subset of the feeling scales from the POM S-BI.

The analogue rating scales consisted of 3 inches $(7.8 \mathrm{~cm})$ horizontal lines, with end points defined as "not at all" and "extremely", and themiddle point as "moderately". The subjects were asked to indicate how intensely they felt each feeling at that moment by putting a cross on the line. The distance of the cross from the origin of the line is taken as the score. $\mathrm{H}$ igher scores represent more intensely felt feelings. Sum scores are obtained for each of the six moods measured by adding the feeling scores for the two respective positive adjectives and subtracting from them the sum of the two respectivenegativeadjectives. Theselfconstructed measurement instrument wasused because it could be devised so as to allow easy and quick administration.

After the mood scale 2 was completed, a room assessment questionnaire, which was composed of thesame type of scales as those in mood questionnaire, was presented for each subject to give an impression of the room. In the room assessment questionnaire, there were 12 scales of environmental impression, including attractive, comfortable, boring, gloomy, ordinary, cheerful, hospitable, stimulating, uninviting, unpleasant, bright, and off putting.

$T$ tests and analysis of variance were used to determine the difference between three different displays and gender in the pre and post tests and feelings ratings change on the mood scales. The t test was also used to examine the difference between the mood scale 1 and 2.

\section{Results}

Therewere some specific changes in the moods and feelings of subjects before entering the room compared to their moods and feelings after being under the treatment condition and viewing the video (Table 1). In the no plant condition, the mean feeling score became lower on the "unsure" scale. In the floral display condition, the mean feeling score became lower on the "unsure" scale and higher on the "annoyed" scale during the experimental period. In the foliage display, therewereno significant changes, however, there was a tendency for the mean mood scoresin the "clearheadedconfused" dimension and the feeling scores on the "clearheaded" scale to become higher.

There were some notable differences in the changes in moods and feelings in the floral display condition compared to the foliage display condition or the no plant condition ( $T$ able 2). U nder the floral display condition, scores were significantly higher on the "annoyed" feeling scale than under the no plant condition. When subject responses under the foliage display condition were compared to those under the no plant condition, scores werehigher on the "bad temper" feel- 
ing scale. In the floral display condition, the mean score changes were significantly higher in the "confidentunsure" mood dimension, and the "agreeable" feeling scale, but lower on the "discouraged", "weak" and "sluggish" feeling scales than those in the foliage display.

$D$ ifferences between the responses of women and men were noted in this study (T able 3). In the no plant condition, the mean scores for males was lower on the "efficient" feeling scale, but higher on the "annoyed" feeling scale, than those for females. In the case of the floral display condition, the mean score for males was significantly lower than that for females on the "clearheaded" feeling scale. In the foliage display, the mean scores for males was higher on the "composed" feeling scale, but lower on the "relaxed", "bad temper" and "unsure" feeling scales than those for females.

On the room assessment questionnaire, no significant differencewas found between the room with the foliage display and the room with no plant condition. H owever the attractiveness of the room with a floral display was rated significantly higher $(\mathrm{p}<$ 0.05 ) than that of the no plant condition (data not shown). Themean score in the floral display was significantly smaller $(p<0.05)$ than that in the foliage display on the "off-putting" scale (data not shown).

\section{Discussion}

This project showed that cut flower displays could affect human emotions. The results on change of mood during the experiment showed that after being in the room with flowers and viewing a videotape, the subjects' feelings of confidence, compo- sure, and relaxation generally increased compared to their feelings before entering the room with the flowers (Tables 1 and 2). Although little scientific work has been done on the concept, perhapsthedecrease of tensenessin thefloral display condition may be attributed to delicate perfume and soft image in the sweet peas (Song and Katagiri, 1992). On the other hand, feelings of annoyance increased in the floral display group compared to feelings in the no plant group (Tables 1 and 2). Kim and Fujii (1996) showed that red and pink colors in petunias could introduce not only cheerfulness and excitement, but al so contributeto emotional instability. The increase in the "annoyed" rating may therefore be due to the excessive colorfulness in the floral display.

Kim and Fujii (1996) suggest that green colors promote emotional sta-

Table 1. C hanges in moods and feelings before entering room compared to moods and feelings after seeing a video in the experimental room with floral, foliage, or no plant display. $P$ values by $t$ test are shown in each condition.

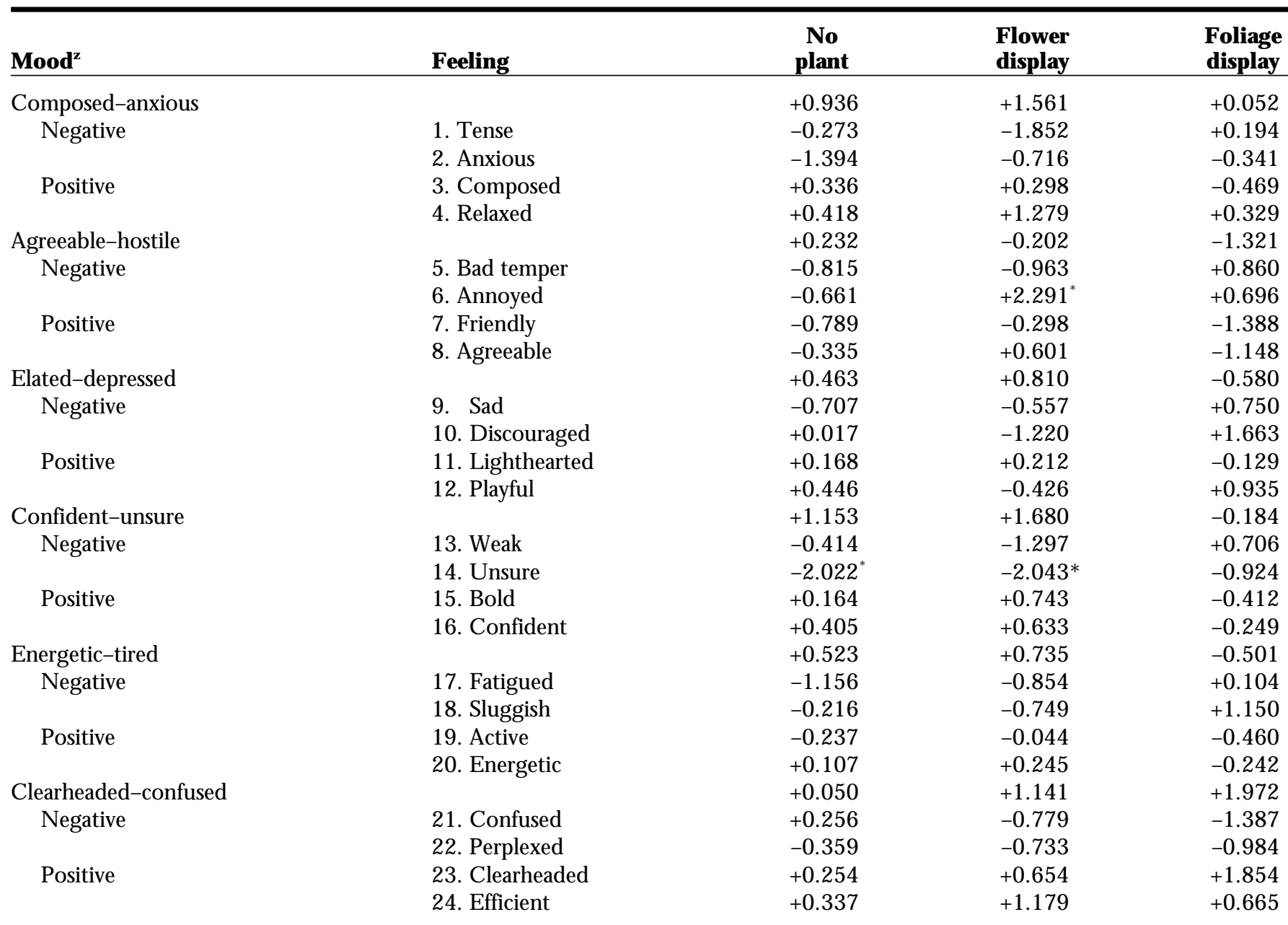

zM ood scores werecalculated by adding scores for two related positive feelings and subtracting two negative feelings. Changewascalculated by subtracting score before exposure to room condition (mood scale 1) from that after exposure to condition (mood scale 2). Change on each feeling was calculated by subtracting score before exposure room condition (mood scale 1) from that after exposure to condition (mood scale 2). Positive $(+)$ and negative $(-)$ effects for a mood and feeling.

${ }^{*}$ Significant at $\mathrm{p}=0.05$. 
bility. Moreover, there are some reports which could explain the positive effect of green plants on human stress in physiological and mental function (Relf, 1992; Coleman and M attson, 1995; Lohr et al., 1996). H owever, the foliage display did not increase relaxation in this experiment (Table 2 ). In contrast, there was a negative effect as the foliage display increased the "bad temper" rating compared to no plants condition. Kim and Fujii (1996) suggest that green colors can introduce depression as well as calmness. Foliage plants might have anegative effect if the subjects were not in a positive mood or not ready to participate in the experiment.

There was a significant negative change on the "unsure" feeling in the no plant condition after being in the treatment room and viewing the video compared to before entering the room
( $T$ able 1 ). 0 ne reason may be that the video images, which themselves used pictures of flowers and plants in the landscape produced an effect. $M$ any researchers have found that slides or photographs of plants can have a positive effect on mental states (U Irich, 1981; Relf, 1992).

Since differencesin reactionsto the environment by gender have been suggested in other work ( $N$ asar, 1988), the differences between men and women were analyzed in this study (Table 3 ). D ifferencesbygender in changein mood and feelings did occur during the experiment. The foliage display generally affected males more positively than females, whilst the floral display and no plant condition had a more positive effect on females (Table3). Someother researchershave found no differencesin response to plants by gender (Lohr et al., 1996). Further study is needed to investigate details of differences in gender in reaction to plants.

\section{Conclusion}

This project showed that floral displays can induce cheerful emotion, however, there are some points to be considered for the future research. This project used questionnaires, due to timeand instrument limitations. H owever, subsequent research can be done with other methods. Physiological and medical measurements, such as electroencephalograph (Kim and Fujii, 1996), skin temperature (C oleman and M attson, 1995), blood pressure, rate of eye opening or heart rate or additional measurement of emotions, e.g. rating behaviour (Talbottet al., 1976), are potentially useful.

This project can be regarded as a preliminary attempt to investigate the effect of floral displayson human emo-

Table 2. Differences in changes of moods and feelings of subjects tested in one room condition compared to those tested in another room condition. $P$ values by $t$ test are shown in A condition vs. B condition (B condition - A condition).

\begin{tabular}{|c|c|c|c|c|}
\hline Mood & Feeling & $\begin{array}{l}\text { No plant } \\
\text { vs. flower }\end{array}$ & $\begin{array}{l}\text { No plant } \\
\text { vs. foliage }\end{array}$ & $\begin{array}{c}\text { Foliage } \\
\text { vs. flower }\end{array}$ \\
\hline Composed-anxious & & +0.691 & -0.907 & +1.427 \\
\hline N egative & 2. Anxious & +0.632 & +1.149 & -0.414 \\
\hline \multirow[t]{2}{*}{ Positive } & 3. Composed & +0.041 & -0.782 & +0.665 \\
\hline & 4. Relaxed & +0.813 & -0.013 & +0.731 \\
\hline N egative & 6. Annoyed & $+2.424^{* *}$ & +1.510 & +0.828 \\
\hline \multirow[t]{2}{*}{ Positive } & 7. Friendly & +0.530 & -0.521 & +1.218 \\
\hline & 8. Agreeable & +1.077 & -0.742 & $+2.446^{* *}$ \\
\hline \multicolumn{2}{|l|}{ Elated-depressed } & +0.135 & -1.007 & +1.007 \\
\hline $\mathrm{N}$ egative & 9. Sad & -1.033 & +1.193 & -1.449 \\
\hline \multirow[t]{2}{*}{ N egative } & 13. Weak & -0.916 & +1.212 & $-2.136^{*}$ \\
\hline & 14. U nsure & +0.085 & +1.243 & -1.329 \\
\hline \multirow[t]{2}{*}{ Positive } & 15. Bold & +0.632 & -0.534 & +1.048 \\
\hline & 16. Confident & +0.360 & -0.748 & +0.989 \\
\hline \multicolumn{2}{|l|}{ Energetic-tired } & +0.273 & -1.693 & +1.766 \\
\hline \multirow[t]{2}{*}{ N egative } & 17. Fatigued & +0.291 & +1.382 & +0.368 \\
\hline & 18. Sluggish & -0.617 & +1.427 & $-2.066^{*}$ \\
\hline \multirow[t]{2}{*}{ Positive } & 19. Active & +0.233 & -0.762 & +0.572 \\
\hline & 20. Energetic & +0.338 & -0.496 & +0.804 \\
\hline \multicolumn{2}{|l|}{ Clearheaded-confused } & +1.287 & +1.732 & -0.351 \\
\hline N egative & 21. Confused & -1.003 & -1.742 & +0.660 \\
\hline
\end{tabular}

$\overline{z M}$ ood scores were calculated by adding scores for two related positive feelings and subtracting two negative feelings. Change was calculated by subtracting score before exposure

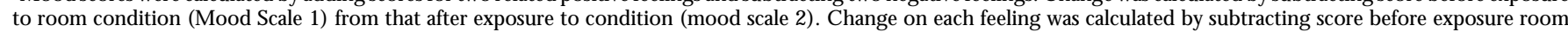
condition (M ood Scale 1) from that after exposure to condition (mood scale 2$).(+)$ and $(-)$ Positive and negative effects for a mood and feeling.

${ }^{*}, *$ Significant at $\mathrm{p}=0.05$ or 0.025 , respectively. 
Table 3. C hanges in moods and feelings under different room conditions for male subjects compared to female subjects. $P$ values by $t$ test are shown in each condition.

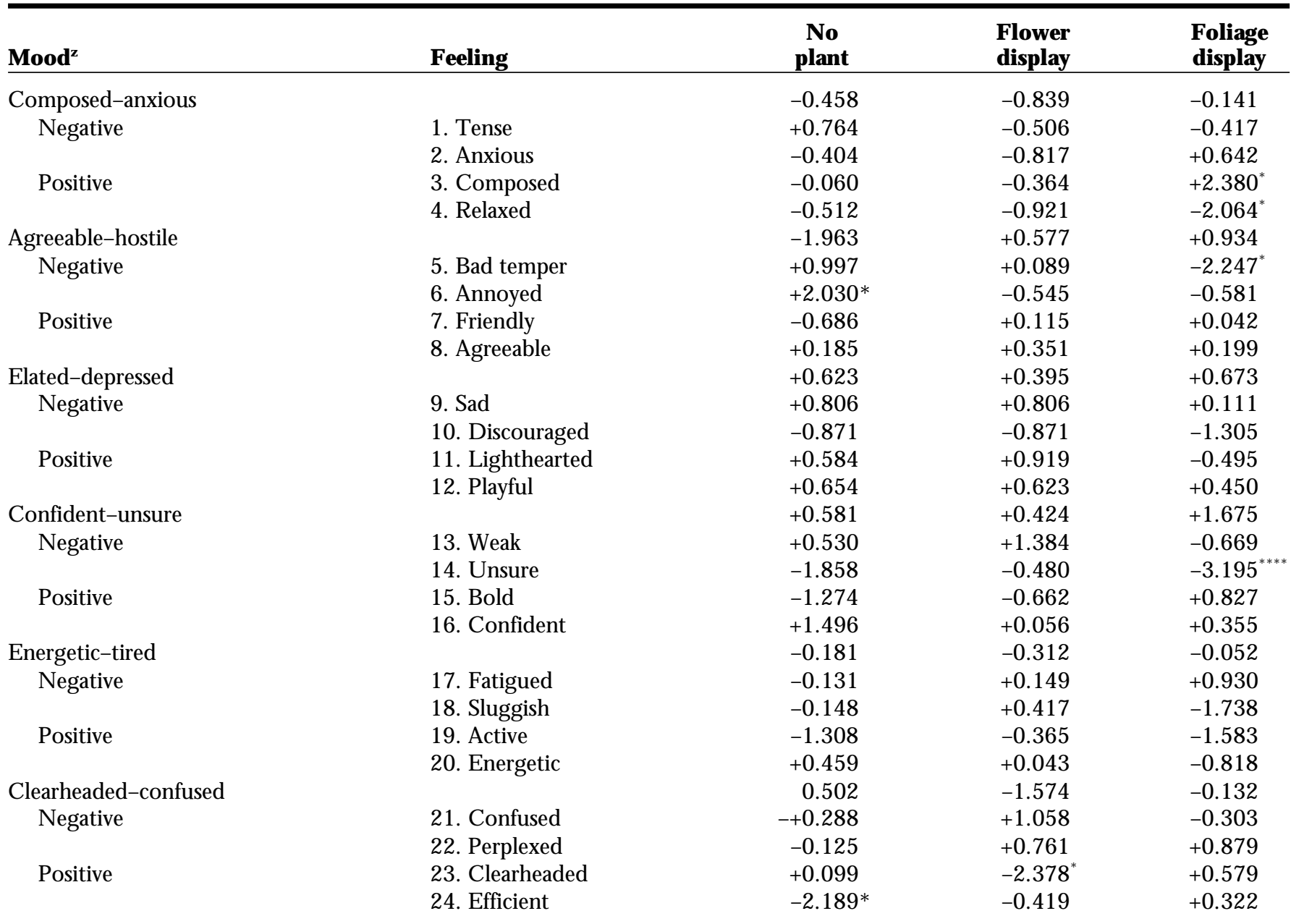

zM ood scores were calculated by adding scores for two related positive feelings and subtracting two negative feelings. $\mathrm{C}$ hange was calculated by subtracting score before exposure to room condition (mood scale 1) from that after exposure to condition (mood scale 2). Change on each feeling was calculated by subtracting score before exposure room condition (mood scale 1) from that after exposure to condition (mood scale 2). (+), (-) Positive and negative effects for a mood and feeling.

****** Significant at $p=0.05$ or 0.005 , respectively.

tions. Such research will doubtless develop as a result of increasing global interest in ecology and psychological responses to the environment.

\section{Literature cited}

Coleman, C.K. and R.H . M attson. 1995. Influencesoffoliage plants on human stress during thermal biofeedback training. $\mathrm{H}$ ortTechnology 5:137-140.

Conklin, E. 1972. M an and plants-A primal association. Amer. Nurseryman 136:42-49.

Doyle, K.O., A.M. H ancheck, and J. M cG rew. 1994. Communication in the language of flowers. $\mathrm{H}$ ortT echnology 4:211-216.

Furuta, T. 1983. Interior landscaping. Reston Publ. Co., Inc., Reston, Va.

Kaplan, S. and R. Kaplan (eds.). 1982. $H$ umanscape: Environments for people.
U lrich's Books, Ann Arbor, M ich.

Kim, E. and E. Fujii. 1996. A fundamental study of physio-psychological effects of the colour of plant (In Japanese). J. J pn. I nst. L andscape Architect. 58:141-144.

Lohr, V.I., C.H . Pearson-M ims, and G.K. Goodwin. 1996. Interior plants may improveworker productivity and reducestress in a windowless environment. J. Environ. H ort. 14:97-100.

Lorr, M. and D.M. M cN air. 1984. Profile of mood states: Bi-Polar Form (POM SBI ) M anual. E duc. Ind. T esting Serv., San Diego, Calif.

M atsuo, E. 1992. Cut-flower usage for ancestral tombsin Kagoshima, J apan. H ortTechnology 2:236-238.

N asar, J.L. 1988. Environmental aesthetics: Theory, research, and application. C ambridge U niv. Press, N ew York.

Relf, D. 1992. H uman issues in horticulture. H ortT echnology 2:159-171.
Rohde, C.L.E. and A.D. Kendle. 1994. $H$ uman well-being, natural landscapes and wildlife in urban areas: A review. Eng. N ature, London.

Shoemaker, C.A., D. Relf, and C. Bryan. 1992. The role of flowers in the bereavement process, p. 43-46. In: D. Relf (ed.). The role of horticulture in human wellbeing and social development. Timber Press, Portland, Ore.

Song, I. and Y. Katagiri. 1992. $\mathrm{H}$ anaryoho (In J apanese). Riyon-sya, T okyo.

Talbott, J.A., D. Stern, J. Ross, and C. Gillen. 1976. Flowering plants as a therapeutic/ environmental agent in a psychiatric hospital. H ortScience 11:365-366.

U Irich, R.S. 1981. N atural versus urban scenes: Some psychological effects. Environ. Behavior 13:523-556.

U Irich, R.S. 1984. View through a window may influence recovery from surgery. Science 224:420-421. 